\title{
DESAFIOS DA \\ DESINSTITUCIONALIZAÇÃO \\ NO CONTEXTO DOS SERVIÇOS SUBSTITUTIVOS DE SAÚDE MENTAL
}

\author{
DESAFÍOS DE LA DESINSTITUCIONALIZACIÓN EN EL CONTEXTO \\ DE LOS SERVICIOS SUSTITUTIVOS DE SALUD MENTAL \\ CHALLENGES IN DE-INSTITUTIONALIZATION PROCESS IN \\ MENTAL HEALTH COMMUNITY SERVICES
}

Julia Bongiovanni ${ }^{1}$ e Rosane Azevedo Neves da Silva ${ }^{1}$

${ }^{1}$ Universidade Federal do Rio Grande do Sul, Porto Alegre/RS, Brasil

RESUMO: A partir da Reforma Psiquiátrica Brasileira (RPB) e da implementação de serviços substitutivos ao modelo manicomial, novas práticas de cuidado aos usuários de saúde mental foram se constituindo. O presente trabalho coloca em questão os desafios da RPB frente aos impasses da desinstitucionalização nos serviços substitutivos. A pesquisa desenvolveu-se em um Centro de Atenção Psicossocial (CAPS), em um município localizado na região metropolitana de Porto Alegre/RS, e utilizou-se a pesquisa-intervenção como estratégia metodológica, apostando na ideia de que conhecimento e prática caminham juntos. Foram realizadas oficinas com um grupo de usuários que possuíam uma longa trajetória de tratamento e de tempo de permanência diária no CAPS a fim de mapear alguns de seus percursos pela cidade e realizar saídas a campo para percorrer esses trajetos. Os efeitos produzidos pela intervenção colocaram em análise a relação com a cidade, a vulnerabilidade econômica dos usuários, além dos desdobramentos produzidos na pesquisadora.

PALAVRAS-CHAVES: Centro de Atenção Psicossocial CAPS; Desinstitucionalização; Saúde mental.

RESUMEN: A partir de la Reforma Psiquiátrica Brasileña (RPB) y de la implementación de servicios sustitutivos al modelo manicomial, nuevas prácticas de cuidado a los usuarios de salud mental se fueron constituyendo. El presente trabajo pone en cuestión los desafíos de la RPB frente a los impasses de la desinstitucionalización en los servicios sustitutivos. La investigación se desarrolló en un Centro de Atención Psicosocial (CAPS) en un municipio ubicado en la región metropolitana de Porto Alegre/RS y se utilizó la investigación-intervención como estrategia metodológica, apostando en la idea de que el conocimiento y la práctica caminan juntos. Se realizaron talleres con un grupo de usuarios que poseían una larga trayectoria de tratamiento y de tiempo de permanencia diaria en el CAPS a fin de mapear algunos de sus recorridos por la ciudad y realizar salidas a campo para recorrer esos trayectos. Los efectos producidos por la intervención pusieron en análisis la relación con la ciudad, la vulnerabilidad económica de los usuarios, además de los desdoblamientos producidos en la investigadora.

PALABRAS CLAVES: Centro de Atención Psicosocial (CAPS); Desinstitucionalización; Salud mental.

ABSTRACT: After the Brazilian Psychiatric Reform (BPR) and the implementation of community-based health facilities replacing the asylum model, new practices of care to mental health users were built. This work inquires the challenges faced by BPR regarding the deistutitionalization in the community-based health facilities. The research was developed at a Psychosocial Care Center (CAPS) in a municipality at Porto Alegre Metropolitan Region. It used the intervention-research approach as a methodological strategy, betting in the idea that knowledge production and practices can walk together. Workshops with a group of long-term CAPS's users, who spent most of their daytime at the health facility, were done. The goal was to map some of the user's preferred routes in the city and then follow these routes with them. The results achieved by this intervention put in analysis the relations with the city, the user's economic vulnerability, and unfolded into the researcher herself.

KEYWORDS: Psychosocial Care Center (CAPS); Deistutitionalization; Mental Health. 


\section{Introdução}

Este artigo coloca em questão os desafios da Reforma Psiquiátrica Brasileira (RPB) frente aos impasses da desinstitucionalização nos serviços substitutivos. Após 30 anos da criação dos Centros de Atenção Psicossocial (CAPS), é necessário olhar para os efeitos produzidos pela desinstitucionalização; a produção de processos de "cronificação" dos usuários nos serviços (principalmente daqueles que têm no CAPS seu único local de convivência), e a necessidade da ampliação da circulação dessas pessoas pela cidade.

Nos diferentes processos da reforma psiquiátrica pelo mundo, a questão da desinstitucionalização foi tomada de distintas maneiras. Entretanto, é necessário ter cautela quando a mesma é equiparada a práticas de desospitalização, não havendo um investimento em um processo social mais amplo. Neste modelo, apesar de haver uma diminuição no período de internação, cresce a reincidência, uma vez que a internação entra como parte de um modo de funcionamento (Amarante, 2007; Rotelli et al., 2001). Para Franco Rotelli et al. (2001), a nova "cronificação" é oriunda de uma prática reformista que produziu a desospitalização, mas não se aprofundou no processo de desinstitucionalização. Desta forma, é mantida uma lógica manicomial fundamentada na dependência e na tutela. Neste contexto, é designado o termo "crônico" aos usuários que se institucionalizam nos novos serviços, independentemente de diagnósticos ou prognósticos atribuídos a essas pessoas. Ou seja, o termo estaria mais atrelado a uma relação restrita entre os sujeitos e os serviços de saúde do que a uma nomenclatura utilizada pela medicina ao se referir a doenças crônicas.

Portanto, a desospitalização alcança o objetivo de não haver mais internação psiquiátrica de longa permanência, o que não significa o término da desinstitucionalização: ao contrário, amplia-se seu campo de atuação, transformando-a em um processo social. Foi o desejo de construir uma nova realidade, a partir da criação de uma rede de atenção extra-hospitalar territorializada, que amparou o surgimento da RPB. Desta forma, os CAPS despontaram como a grande aposta para a produção de novas práticas de cuidado em saúde mental.

Porém, se a Reforma Psiquiátrica busca construir outro lugar para a loucura, parece prudente estar atento para saber que local é esse. Como não tornar o CAPS o único lugar possível? Sabe-se que a desinstitucionalização não se esgota no processo de desospitalização e que os serviços substitutivos podem vir a reproduzir a lógica manicomial, fazendo com que a cronicidade se atualize de outra maneira.

A negação da instituição não é a negação da doença mental, nem a negação da psiquiatria, tampouco o simples fechamento do hospital psiquiátrico, mas uma coisa muito mais complexa, que diz respeito fundamentalmente à negação do mandato que as instituições da sociedade delegam à psiquiatria para isolar, exorcizar, negar e anular os sujeitos à margem da normalidade social. (Rotelli \& Amarante, 1992, p. 44)

Torna-se importante frisar a necessidade de oferta de cuidado para as pessoas que se encontram em sofrimento psíquico. Entretanto, é preciso olhar para o processo de desinstitucionalização não apenas como o fechamento de hospitais psiquiátricos, mas, sobretudo, proporcionar uma reflexão sobre os processos de segregação, historicamente produzidos em torno da loucura. Alverga e Dimenstein (2006) apontam que, nos últimos anos, o direcionamento da saúde mental para a inclusão dos excluídos esteve baseado no ideal de uma sociedade igualitá- 
ria e no resgate da cidadania dessas pessoas. Destacam a importância da reinserção social e a produção de autonomia do usuário para a continuidade do processo de desinstitucionalização.

É inegável a importância dos CAPS no processo da RPB, principalmente em sua potência de oferta de cuidado em liberdade, mas é necessário olhar para sua fragilidade em conseguir fomentar uma transformação social. Segundo documento do Ministério da Saúde publicado em 2004, "Saúde mental no SUS: os centros de atenção psicossocial”, caberia ao CAPS o papel de articular a rede em seus diversos âmbitos, ofertando o atendimento à população de sua área de abrangência e promovendo a "reinserção social dos usuários pelo acesso ao trabalho, lazer, exercício dos direitos civis e fortalecimento dos laços familiares e comunitários" (Ministério da Saúde, 2004, p. 13). Portanto, se o serviço tem como objetivo promover a articulação, a circulação e a inserção de seus usuários em seus territórios, ou seja, produzir novas possibilidades, o fato de tornar-se o principal (e às vezes, o único) lugar de inserção dos mesmos parece contraditório. Neste mesmo documento é ressaltada a necessidade de a equipe olhar para cada usuário de forma singular e traçar (conjuntamente com o usuário) seu plano terapêutico, estando atenta às diferentes intensidades de tratamento que cada pessoa necessita. Para dar conta destas questões, geralmente os CAPS fornecem uma grade de atividades variadas, incluindo: oficinas, grupos terapêuticos, atividades de lazer, passeios, atendimentos individuais, etc. Há, porém, o risco desse projeto terapêutico tornar-se um projeto de vida restrito ao que é proporcionado pelo serviço, e de os usuários terem no CAPS seu único lugar de socialização.

Nos últimos anos, houve reformulações na política de saúde mental como a portaria $n^{0}$ 3.088/2011) que institui a Rede de Atenção Psicossocial (RAPS), por considerar a necessidade de ampliação e de articulação dos pontos de atenção à saúde. Esse documento tem, entre suas diretrizes, a diversificação das estratégias de cuidado, além da inclusão social a partir do desenvolvimento de atividades no território, apontando como um de seus objetivos a promoção do acesso dos usuários a diferentes pontos de atenção. Entretanto, se, no decorrer dos anos, a legislação aponta para a necessidade de ampliação da rede de cuidado e a busca pelo desenvolvimento de ações integrais em saúde de modo que o CAPS não ocupe lugar de exclusividade, a centralidade dada a tais serviços ainda é um grande obstáculo (Eslabão et al., 2017; Lima \& Dimenstein, 2016).

Dentro de um contexto onde a forma vigente de desinstitucionalização acaba por produzir novas formas de institucionalização, como operar com o resíduo manicomial que independe do espaço físico? Enquanto as ações ficarem restritas a um único serviço parece que esta situação se perpetuará. Questionar-se sobre em que medida o CAPS estaria operando como um serviço substitutivo dentro de uma rede maior, e como ampliar os itinerários possíveis de serem percorridos (saindo do trajeto casa/CAPS), torna-se importante.

\section{Cidade e loucura}

É necessário olhar para essas questões permanecendo atentos ao que ocorre fora dos serviços: estaria a cidade acolhendo esses usuários? A existência de uma lógica manicomial presente nos processos de subjetivação e influenciando os modos de se habitar a cidade, permitiria pressupor que a relação loucura e cidade pode ser vista como um analisador da desinstitucionalização (Amorim \& Dimenstein, 2009). Afinal, no contemporâneo, a figura do louco ainda está associada à doença mental e tem seu espaço de circulação restrito. 
Entretanto, a cidade da atualidade não é mais vista como espaço promovedor de encontros, deseja-se agora uma circulação fluída com menos paradas. Mizoguchi (2009, p. 14) fala do imperativo do medo e do paradoxo produzido na relação da loucura com a cidade contemporânea: "em uma época essencialmente marcada por privatizações e individualismos, a segregação dá-se não mais pelo encarceramento dos anormais em espaços fechados, mas sim pela exclusividade da permissão à infiltração e ao deslocamento".

Os muros que antes serviam para impedir a saída, como os do hospício que aprisionavam os loucos, são agora utilizados para impedir a entrada e promover o convívio entre iguais como, por exemplo, nos grandes condomínios: "A autorreclusão dos iguais, ao invés do aprisionamento dos distintos, se dá com a proliferação de espaços privados e público-privados cada vez mais autônomos em sua subsistência cotidiana de serviços e lazeres" (Costa \& Fonseca, 2013, p. 26). Nesta "lógica dos condomínios", apresentada por Dunker (2004), na qual se atualiza o desejo de estar entre "iguais", cria-se um estado especial de lei que irá fomentar rígidos regulamentos internos, garantindo segurança e proteção. Desta forma, a existência do condomínio implica o reconhecimento da barbárie, daquilo que não pertence aos "iguais", ou seja, os excluídos.

A falta de determinados espaços urbanos não parece ser "privilégio" apenas dos loucos. Esse esvaziamento dos laços comunitários perpassa a sociedade contemporânea como um todo. Assim, haveria um desafio ainda maior para os usuários de serviços de saúde mental: superar os estigmas na construção de novas redes e se inserir em um contexto no qual cada vez há mais enfraquecimento das trocas e dos encontros (Salles \& Miranda, 2016).

Guattari (1992) fala da cidade subjetiva atravessada por níveis singulares e coletivos das pessoas; a cidade como uma grande máquina que produz subjetividade. É necessário inventar uma democracia em que todos tomem a palavra em relação à cidade. "É o socius, em toda sua complexidade, que exige ser re-singularizado, re-trabalhado, re-experimentado" (Guattari, 1992, p. 176). Uma cidade subjetiva em sua processualidade, aberta à invenção, ao heterogêneo.

Décadas após o início da RPB, com o gradual fechamento dos manicômios e após uma série de conquistas políticas no campo da saúde, as questões surgem em outra dimensão: é possível produzir brechas na cidade para promover o encontro com a diferença? Como as ações dos serviços de saúde mental podem reverberar no território? Ao olhar para o processo de "cronificação", coloca-se um novo desafio para os serviços substitutivos: buscar outros itinerários a serem percorridos, outros espaços a serem habitados.

\section{O percurso metodológico}

A questão que moveu esta pesquisa emergiu do cotidiano de trabalho da pesquisadora, ao olhar para os usuários que tinham o CAPS como único local de convivência. Começaram a surgir indagações sobre qual o motivo para a falta de circulação pela cidade, se os serviços substitutivos acabariam por perpetuar práticas que "cronificam" os usuários de saúde mental e se a ampliação dos laços sociais poderia ser um “antídoto” para isso.

Com esses questionamentos, utilizando-se da pesquisa-intervenção, com o objetivo de promover a ampliação da circulação pelo território dos usuários que possuem uma longa trajetória de tratamento e de tempo de permanência diária no CAPS, criou-se uma oficina com um grupo de usuários para experimentar outros itinerários de desinstitucionalização. 
A pesquisa-intervenção tem origem na análise institucional e inova ao desconstruir a relação de neutralidade entre o pesquisador e seu campo, problematizando a relação sujeito/ objeto. Nesse sentido, o ato de pesquisar pressupõe uma intervenção em uma via de mão dupla: produz-se mudança no campo e no pesquisador (Paulon, 2005). Trata-se de uma aposta em pesquisar "com" os participantes e não "sobre" eles, cujo objetivo não é representar uma realidade, mas tentar conhecê-la (Kastrup, 2008).

Portanto, a escolha por essa metodologia de pesquisa deu-se por sua potência em acompanhar movimentos, produzir rupturas, tanto na pesquisadora que, mobilizada por seu dia-a-dia de trabalho, buscava desnaturalizar fazeres e saberes já automatizados, quanto nos usuários, que pareciam ter se "cronificado" em suas rotinas. Assim, convidamos cinco usuários para participar de uma oficina na qual, utilizando um mapa do município, cada participante narrasse os seus percursos habituais e pudesse assinalar no mapa suas trajetórias pela cidade. A proposta era compartilhar e repensar os diferentes espaços de circulação. Em um segundo momento, pensou-se que o grupo pudesse percorrer esses trajetos, conhecendo o percurso de cada um, indo a campo, abrindo-se àquilo que acontece ao caminhar pela cidade. Em um terceiro momento, construir um mapa comum a partir desses diferentes itinerários e ver o que de novo surgiria. Além da troca e da possibilidade de conhecer os trajetos de outros participantes da oficina, também estaríamos abertos ao imprevisível, ao que fosse surgindo durante as caminhadas.

No decorrer dos seis meses em que o grupo se reuniu, os encontros foram se alternando entre momentos os quais se permanecia no CAPS conversando e outros em que aconteciam as saídas para a rua. Nas ocasiões em que se permanecia no CAPS, a maioria das vezes, o assunto girava em torno da cidade, sendo colocados no mapa os pontos visitados, planejando-se também os próximos destinos. Em alguns momentos, houve pausas para dar suporte a algum dos participantes que estava passando por uma situação difícil e via no grupo a possibilidade de compartilhar seu sofrimento.

\section{Discussão dos resultados}

Esta pesquisa foi desenvolvida em pequeno município situado na região metropolitana de Porto Alegre/RS. A cidade tem uma população de aproximadamente 85.000 habitantes e o PIB per capita em torno de $\mathrm{R} \$ 35.000,00$, sendo a sede de inúmeras empresas. Mas, se o município desponta com um alto indicador de renda, isso não se reflete em sua infraestrutura. Diferentemente do que se pode esperar em função desses dados, não se trata de cidade suntuosa, não havendo vestígio de riqueza nas casas ou nos estabelecimentos comerciais. Ao contrário, a cidade possui dois grandes bolsões de pobreza, apesar de seu pequeno território. Idiossincrasias do capitalismo: o local que gera o capital nem sempre é o mesmo que usufrui dele. Além disso, a facilidade de locomoção proporcionada pelo trem (que liga diversas cidades da região metropolitana) faz com que muitos dos moradores trabalhem em outros locais, principalmente em Porto Alegre e, em função do custo de vida mais barato, residam no município, dando um caráter de "cidade-dormitório" à mesma. As opções de lazer também são restritas, o local não conta com cinemas, shoppings ou com uma vida noturna agitada, sendo muito comum seus moradores buscarem atividades de lazer nas cidades vizinhas.

A partir dos encontros produzidos durante as saídas a campo, alguns desdobramentos foram sendo engendrados ao nos depararmos com a cidade, nos levando a pensar a "cronicidade" de uma outra perspectiva. 


\section{croniCIDADES}

Logo no início das saídas realizadas pelo grupo, começaram a surgir alguns indícios da relação com a cidade; não se tratava de um desconhecimento sobre os espaços existentes no município ou uma dificuldade de se articular em busca de informação. Pelo contrário, o grupo demonstrava bastante desenvoltura: dominavam os trajetos, não se constrangiam ao acessar os diferentes lugares. Entretanto, os lugares pareciam esvaziados: praças com pouquíssimas pessoas, igrejas fechadas no horário em que o grupo acontecia (horário que os usuários frequentam o CAPS), ou seja, poucos atrativos para quem está passeando sozinho, expressando um esvaziamento da possibilidade de produção de encontros.

O esvaziamento do espaço público é típico das cidades contemporâneas, os espaços de convivência tornam-se cada vez mais privatizados (shoppings, clubes, bares, etc.), restando à rua o lugar de passagem, um meio para acessar outros lugares, de preferência em carros para evitar ao máximo um possível contato com o outro. Frente a essa experiência com o urbano, cada vez mais restrita, o que inicialmente aparecia como um confinamento acaba surgindo como uma possibilidade. O CAPS era um dos poucos lugares para se estar com outras pessoas, e, nas saídas do grupo, ficou mais nítida sua potência como espaço articulador de encontros e uma via para a circulação pela cidade.

Nesse encontro com o urbano, vão surgindo pistas de um dos desdobramentos da pesquisa: se tomamos a "cronicidade" não apenas pela patologia, pelo diagnóstico, mas associada ao tempo, por uma relação de longa duração com o serviço - a ideia de institucionalização -, emerge um novo aspecto em nossas questões: a própria cidade que também se “cronifica”. Quando não há mais nada para se fazer, o CAPS ainda é um lugar interessante.

Além disso, foram recorrentes as conversas em torno das agressões que os participantes sofreram pela polícia e dos "paredões" pelos quais passaram. A polícia, a serviço da manutenção da segregação, antevendo algum possível risco: não é um ato que justifica a violência, mas a possibilidade de que algo desestabilize a "ordem". Um medo instaurado que vem justamente tirando a potência da polis como espaço de encontro, de troca. Uma certa paranoia onde o "inimigo" sempre pode estar ao lado. Na cidade contemporânea, os asilos e o encarceramento dos anormais não são a principal forma de segregação, outros dispositivos disciplinares são utilizados para a manutenção da "segurança" de seus habitantes, à pretensão de paz revestida pelo higienismo.

Além do fator classe social, é necessário olhar para a interseccionalidade ao pensar na violência sofrida por essas pessoas. A grande maioria dos participantes do grupo era de homens negros. Marcas do racismo institucional no campo da segurança pública brasileira e da filtragem racial na abordagem de suspeitos (Barros, 2008; Sinhoretto et al., 2014).

Em contraponto, uma determinada praça despontou como unanimidade para o grupo quando o assunto referia-se a "locais que gostam de frequentar". Um pequeno espaço na região mais central da cidade que parece acolher diferentes pessoas, moradores de rua, gente que marca encontros, ou "faz hora" para algum compromisso. Ali, o recorte de classes parece minimizado. É comum ver alguém sozinho lendo o jornal ou navegando no celular. E, como é típico em cidades menores, com frequência é possível encontrar algum conhecido ao acaso.

Essa praça foi bastante citada e foi relacionada ao fato de "olhar o movimento", atividade que o grupo apontou como uma possibilidade quando não se tem dinheiro. Assim, a 
"falta do que fazer" também está vinculada à falta de dinheiro. Todos os passeios realizados foram em locais em que a entrada era gratuita. Além disso, nenhum dos espaços era voltado diretamente para o consumo (restaurante, lojas etc.). Ao mostrarem "sua cidade", apresentaram, também, a dificuldade de inserção nos espaços de lazer; afinal, na maioria das vezes, a "diversão" no nosso modo de subjetivação capitalista está relacionada ao consumo.

A cidade que discrimina os grupos sociais também apareceu em diferentes conversas, explicitando a segregação, agora não mais pelo aprisionamento dos diferentes, mas pela dificuldade de acesso a territórios onde o capital é quem regula a entrada. A questão econômica emerge como elemento de segregação, uma vez que a entrada só é possível "pela porta dos fundos", ou seja, não mais pelo estigma da loucura, mas pelas marcas da pobreza.

A cidade e seus diferentes tempos também surgiram como um analisador. Uma sensação de nostalgia permeou os encontros, tanto pelas falas que remetiam a uma cidade "de antigamente", quanto pela relação com o urbano, pelo desejo por uma época onde a velocidade parecia ser outra. A cidade, dos tempos atuais, trazia consigo certo tom de amedrontamento aos participantes, a ida à capital, por exemplo, era relatada como algo temeroso. Se em alguns momentos a nostalgia parecia estar relacionada à idade e a um tempo cronológico, visto que quase todos tinham entre 50/60 anos, algumas falas apontavam para uma outra noção de tempo, um tempo que soava distante, mas não pela passagem dos anos. Muitos dos relatos do passado estavam associados a um período ainda não marcado pelas internações, pelo tratamento em saúde mental. Será que esse tempo nostálgico não estaria no passado ainda não marcado pela doença? É comum o fato de pessoas que passaram por episódios de intermação ou de intenso sofrimento psíquico resgatarem um período da sua vida onde a relação com a patologia, com a Classificação Internacional de Doenças (CID), não estava presente. Frases como: “quando eu era são...”, “quando eu não era doente...”, surgiram no grupo, mas não ficam restritos a ele. Frases que transmitem uma sensação de ruptura precoce. Comumente escutam-se pessoas com uma idade avançada falando de um passado produtivo, pois, para tais sujeitos, o "passado produtivo" teve um encurtamento marcado pela doença.

Os destinos percorridos pelo grupo também eram demarcados por tempos distintos. Havia uma diferença entre as caminhadas dentro dos bairros em relação àquelas na avenida central da cidade. Nesta última, andava-se em fila, em um passo apressado, a conversa diminuía, quase como se não estivessem em grupo. Já em espaços mais afastados das grandes vias, as conversas seguiam em outro ritmo, mais de uma vez foi preciso "cuidar o relógio” para que o tempo de retorno ao CAPS não ultrapassasse muito do combinado. Entretanto, essa diferença entre os tempos, apesar de percebida e até mesmo apreciada, não era tomada como algo ruim pelos participantes; a industrialização, nas falas deles, era trazida também como sinônimo de progresso.

Em uma entrevista, Paul Virilio (2012) afirma o poder da velocidade na sociedade capitalista: afinal, riqueza e velocidade estão interligadas e a acumulação do capital passa pela aceleração na lógica do "tempo é dinheiro". O autor exemplifica com as negociações financeiras na era da Internet, onde segundos podem gerar a perda de milhões em operações: como exemplo, cita o ocorrido, no dia 6 de maio de 2010, em Wall Street quando um grande número de operações realizadas em um curto espaço de tempo provocou uma pane que acarretou na perda de bilhões de dólares. Assim, a velocidade é tida como a "propaganda do progresso”, e o século XXI volta-se para a conquista do tempo infinitesimal. 
Além disso, a peculiaridade com que a psicose vivencia as questões de espaço e tempo deve ser levada em conta quando olhamos para a relação que esses sujeitos estabelecem com a cidade. Se a afobação e a aceleração da rua parecem assustar, acolher um ritmo diferente e promover uma parada nos fluxos intensos é importante. Nesse sentido, o CAPS pode assumir o papel de intermediador entre o serviço e a cidade em seus diferentes ritmos, o que potencializaria habitar o urbano de forma ampla. Entretanto, não parece só uma questão de "adaptar" os usuários de saúde mental ao ritmo das cidades contemporâneas. A velocidade frenética da cidade e a otimização do tempo são um imperativo do capitalismo. Nessa lógica, o tempo torna-se um bem, uma mercadoria, cada segundo a mais de produção pode gerar mais lucro. Peter Pál Pelbart, em seu livro A nau do tempo-rei (1993), associa essa possibilidade de dar uma "parada" no tempo - peculiar à loucura - a um ato grevista, um movimento de resistência a essa aceleração e à demanda de produtividade que impera. Não se trata de inserir os loucos na lógica do tempo da urgência, mas, por que não, compartilhar dessas outras temporalidades ao habitar o urbano? O que o tempo da loucura teria a nos dizer?

Outra característica do grupo, talvez, mais do que conhecer novos locais, foi a possibilidade de revisitar espaços, de atualizar a memória e trazer vida a lugares já esquecidos. Nestes percursos fomos surpreendidos: três dos nossos destinos não existiam mais, ou não eram mais acessíveis ao público. Apesar de certo tom de ressentimento que essa situação trouxe para algumas das conversas, a tentativa de revisitar a "cidade do passado" também rendeu muitas lembranças boas e teve a função de promover uma espécie de pertencimento ao grupo. Eles compartilhavam o conhecimento sobre algo que já não poderia mais ser visto.

\section{“Crônicos”?}

A alguns usuários de saúde mental é atribuído o termo "crônico", tanto pela inalcançável "cura" quanto, principalmente, por aquilo que perdura, que se arrasta ao longo do tempo sem muita perspectiva de mudança, de um prognóstico positivo. Os "crônicos" necessitariam de um cuidado em saúde por longos períodos, o que justificaria permanecerem por tanto tempo nos serviços. Talvez mais "supervisionados" do que investidos de cuidado, por isso é tão comum o CAPS servir mais como um espaço de convivência do que de local de "tratamento" para essas pessoas, ou seja, uma função diferente daquela que se poderia tradicionalmente esperar dos equipamentos de saúde.

Entretanto, com o decorrer da pesquisa, produziu-se uma relativização da própria "cronicidade" daquelas pessoas. Corpos supostamente docilizados demonstraram-se mais desejantes do que se imaginava. Como exemplo, as faltas posteriormente justificadas pelo mau tempo, algum "bico" feito na vizinhança, etc. A chuva ou a necessidade de ir ao banco tinham um lugar de prioridade, algumas coisas não sendo mudadas para se adaptar à rotina do CAPS. A afirmação "se não tivesse o CAPS ia ficar em casa dormindo" surgia como unanimidade para o grupo, mas também é demarcada como uma opção.

Percebeu-se também o quanto a sensação de marasmo, atribuída ao fato de aquelas pessoas passarem anos frequentando o mesmo serviço, pode ser equivocada. Visto de outra perspectiva, aquele espaço, que parecia homogêneo, possui multiplicidades. Em um dado momento, quando foi questionado o fato de os usuários ficarem restritos ao trajeto de casa para o CAPS, um dos participantes contou que ele fazia isso, mas complementou: "o CAPS 
mudou muito nos últimos anos!", o grupo pode falar sobre as mudanças dos profissionais no serviço, das diferentes casas que o CAPS ocupou nos últimos anos e do fato de apenas duas profissionais estarem trabalhando desde a sua implementação na cidade. Demarcaram que, apesar de frequentarem o serviço há muitos anos, não se tratava sempre do mesmo espaço. Conseguiam ver movimento em algo que os trabalhadores olhavam como estagnação: não era o "mesmo" CAPS que frequentavam durante esses anos e justamente por estarem há mais tempo no local é que conseguiam ver o que de novo havia nele.

O objetivo da pesquisa não era apenas acompanhar os usuários, mas também produzir intervenção nos espaços por onde eles circulavam, acreditando que a desinstitucionalização também está relacionada a como essas pessoas fariam a sua inscrição no social. Não só o que a cidade coloca para o CAPS, mas o que o CAPS coloca para a cidade. Contudo, durante os percursos, o medo e a falta de aceitação da loucura não despontaram como impeditivos para a circulação do grupo, não tendo sido percebido nenhum tipo de preconceito gerado pelo fato de serem usuários de saúde mental. Talvez a presença de um profissional de um serviço de saúde serviu como um facilitador para o processo de circulação nos diferentes espaços. Entretanto, isso não parece ter sido a questão principal. $\mathrm{O}$ atravessamento de classe parece ter se sobressaído em relação à loucura.

Questões relacionadas à garantia de direitos também apareceram nas conversas. Quanto ao deslocamento pela cidade, dos cinco participantes, quatro possuíam "passe livre”. Mas esse passeio de transporte público é acompanhado por uma certa cautela, utilizando apenas as lotações que passam em frente a suas casas, e o destino final é o centro da cidade; como em uma obediência às rotas previamente estabelecidas pela companhia de transporte público. Apenas um dos participantes não recebia o Benefício de Prestação Continuada (BPC) ou aposentadoria por invalidez, porém estava, com o auxílio de um advogado, reivindicando seu direito. Com esse dinheiro, além de seu próprio sustento, eles auxiliavam suas famílias e, em um caso, era a única fonte de renda para todos (mãe, irmã, cunhado e sobrinhos).

Outro relato bastante presente na fala de um dos participantes (que tinha em torno de 30 anos de idade) era a "falta do que fazer" em seu território, mesmo sendo um local de bastante investimento em termos de políticas públicas. Apesar de existirem diferentes recursos no local, nenhum era voltado para sua faixa etária. Reflexo da nossa sociedade e do não lugar para aqueles que estão em idade produtiva para o trabalho, mas estão fora dele. Também da nossa, ainda escassa, política de inclusão para o emprego, onde aqueles que destoam dificilmente conseguirão brechas para atuar em um mercado formal. Além disso, as poucas possibilidades de inserção no trabalho - sendo formal ou não - estavam relacionadas a atividades que exigem grande esforço físico, com uma contrapartida muito baixa de remuneração.

Assim, a "cronificação" também estaria associada a uma série de desinvestimentos. Ao olharmos para os usuários que frequentam o CAPS com maior assiduidade, percebe-se que, na maioria das vezes, são pessoas com baixa escolaridade, em vulnerabilidade social e que o serviço, além de promover o cuidado em saúde mental, também é um espaço para realizar refeições, tomar banho etc.

Durante a realização do grupo, a escassez de espaços de convivência na cidade ficou evidente, e o CAPS mostrou-se como um suporte relevante em momentos difíceis, uma opção para quando havia brigas em casa, por exemplo, mas também um espaço para se frequentar quando não se "tinha nada para fazer". A necessidade de ter um lugar para ir 
todos os dias e "passar o tempo" foi trazida em diversos momentos pelos participantes. Entretanto, o ato de "passar o tempo" é o que justamente acabaria atribuindo o caráter "cronificante" a eles. O tempo livre, na contemporaneidade, é tido como algo problemático. No imperativo do ritmo acelerado, a ociosidade é encarada como perda de tempo, esse - como já dito antes - quando tomado como um bem, uma mercadoria que deve ser constantemente otimizada. Talvez o motivo pelo qual os profissionais de saúde demonstrem incômodo com o modo de estar no CAPS e tentarem preencher o tempo dos usuários com diferentes atividades. Estar em um local, por um longo período "sem fazer nada", não parece plausível atualmente.

Se, por um lado, havia uma falta de opção, também existia uma certa resistência em circular em outros lugares. Mesmo convites aparentemente atrativos, como a festa patrocinada pelo município em seu aniversário (sem articulação com o grupo), ou o Baile da Terceira Idade em que os participantes foram convidados (e só um compareceu), o novo parece não ser muito interessante. Entretanto, a possibilidade de estar com essa pessoa no baile, e vê-la posteriormente contagiando seus colegas para acompanhá-la em um próximo, dá pistas de um trabalho a ser feito pelo CAPS. Acompanhar essa circulação pela cidade, pois, se não há pessoas nas praças, por que não ocupá-las? Talvez com atividades externas a cidade também possa tornar-se mais atrativa.

Estar entre a instituição e o urbano é o que propõe o Acompanhamento Terapêutico (AT) como modalidade clínica:

na medida que possibilita acompanhar o sujeito na sua circulação pela cidade, colocando-se como alternativa para a construção de um espaço transicional, uma zona de intermediação entre a referência institucional para esse sujeito e seu acesso à via e aos lugares públicos. (Palombini et al., 2008, p. 17)

O CAPS poderia emprestar essa função AT e auxiliar para que os espaços públicos sejam habitados e não apenas transitados, que lugares de passagem se tornem espaços de convivência. Algo também a ser feito em grupo, para além das questões clínicas, um dispositivo a serviço da apropriação da cidade.

Outros questionamentos foram surgindo em relação à dificuldade em sair do CAPS; a primeira saída do grupo, por exemplo, demorou um mês para acontecer. Geralmente, as atividades externas são organizadas pelos técnicos, sem muita intervenção dos usuários. Fora a escolha do destino, toda a organização é feita sem que os usuários participem do processo. No entanto, a demanda neste grupo era diferente: eles deveriam escolher o local e planejar como chegariam (se usariam transporte público ou iriam a pé, se daria tempo de fazer a atividade em uma manhã etc.). Isto aponta para a própria falta de hábito dos profissionais em sair do serviço, pois realizar essa circulação pela cidade pode ser difícil e trabalhosa, fazendo com que também os trabalhadores se acomodem, se institucionalizando, visto que esperar que os usuários venham até o CAPS, realizem uma atividade e voltem para casa demanda bem menos tempo e planejamento. Mas por que não compartilhar essa tarefa? Dividir a responsabilidade da circulação pelo território com o usuário poderia diminuir essa inércia.

A pesquisa iniciou com as premissas de que a cidade não acolheria a loucura, que o CAPS "cronificaria” os usuários e que haveria uma dificuldade por parte dessas pessoas em circular pelo urbano. Porém, o grupo despontou como um dispositivo no qual as expe- 
riências locais puderam ser postas em análise (Rocha \& Aguiar, 2003); ocupar o lugar de pesquisadora possibilitou repensar o papel de trabalhadora. Poder olhar para os efeitos da relação técnico/usuários e os reflexos dessa nas relações de saber/poder no cotidiano do serviço, colocando em questão alguns dos pensamentos naturalizados, ideias preconcebidas e não verificadas, atravessamentos na relação profissional/usuários.

\section{CAPS para além da desospitalização}

Pensar o CAPS como local que perpetua a "cronicidade" e a relação com a cidade como algo embrutecido parece não dar conta das problemáticas aqui levantadas. Também apontar que "não se tem rede" pode soar como uma saída fácil para esse problema. O que nos parece mais interessante é poder habitar o que existe para além dos serviços. Se a cidade atualmente é tomada como espaço de passagem, contrária ao encontro, caberia também ao CAPS propor atividades em outro tempo. Poder efetivamente trabalhar no território, fazer redes, incluindo essa diferença, sustentando outros lugares possíveis.

No decorrer dos encontros, os usuários foram mostrando os lugares que existiam em sua cidade e que havia um esvaziamento de sentido nos espaços de convivência, mais do que uma falta de acolhimento por parte do urbano. Um desdobramento na questão inicial: a cidade também "cronifica". Também mostraram que fazer a mesma coisa todos os dias não é necessariamente algo a ser combatido. Seguir o imperativo: fazer a mesma coisa todos os dias pode ser resistência, sendo nômade quando não se move, mas quando se habita o espaço. O CAPS podendo operar como lugar de parada. O tempo dos usuários como uma forma de resistência quando uma circulação mais ampla pode estar atrelada a um imperativo de movimento, resistência a essa velocidade do urbano que nos invade. O CAPS atuando dentro dessa "lógica de condomínio" como um espaço de troca entre os pares e de proteção.

O dinheiro também surgiu como um importante analisador: a restrição ao circular no urbano estaria relacionada à loucura ou à pobreza? Dinheiro como um ponto nevrálgico; sabe-se que a grande maioria de usuários dos serviços de saúde mental pertencente ao SUS também é atravessada por um recorte de classe, de um grau de escolaridade. Se a vida citadina, em nosso modo de subjetivação contemporâneo, perpassa pelo poder aquisitivo, não seria diferente com os participantes do grupo.

Assim, se esses "novos crônicos" não carregam marcas dos hospitais psiquiátricos (roupas identificadas), carregam a marca da pobreza. Torna-se necessário olhar para a questão não se restringindo ao campo da saúde, pensando também em ações intersetoriais. Se, em sua maioria, os usuários de saúde mental do SUS possuem baixa escolaridade e possibilidades precárias de emprego, como estreitar relações e promover ações vinculadas à educação e ao trabalho? Não olhar a doença de forma isolada (separando-a do social) era um dos lemas defendidos pelos psiquiatras italianos. Poder falar sobre loucura e relacioná-la com outros marcadores de exclusão é uma forma de ampliar a questão e não limitá-la ao patológico.

No decorrer da pesquisa, percebeu-se que o CAPS ainda é um equipamento de sociabilidade importante, ao menos no município em questão, pela pouca diversidade de espaços voltados ao lazer. Com isso, pretendemos deixar claro que não se trata de uma generalização. Provavelmente em outros municípios, com dispositivos diferentes, a relação de usuários de saúde mental e a cidade pode se dar de outra forma. 
Na rotina de um serviço de saúde é importante que os profissionais fiquem atentos a outros dispositivos da cidade, sendo propositivos na apresentação e construção de novos espaços a serem experimentados. Compartilhar o planejamento dessas atividades com os usuários, abrir-se para o conhecimento dos mesmos sobre seus territórios, tornar isso um processo a ser feito conjuntamente também ampliaria possibilidades de circulação pelo urbano. Trata-se, portanto, de tirar esse tipo de dispositivo, o sair para rua, de sua excepcionalidade, incorporando-o à rotina do serviço.

Nessa forma de conceber a desinstitucionalização, tomando-a pelo seu conceito ampliado, o grande desafio do CAPS é deslocar-se da função de ser "o lugar" de cuidado para os usuários de saúde mental por conta de seu saber especializado, de uma centralidade biomédica, e retomar sua potência como agenciador na construção de um "outro lugar social para a loucura”, apostando no cuidado, nas trocas, nos espaços de encontro. Incumbir-se da função de auxiliar nessa relação com uma cidade contemporânea onde o acesso é limitado quando há falta de dinheiro, tornando os espaços públicos esvaziados. Inventar novos modos de habitá-la, tensionar essas dificuldades, olhando para o urbano também pela sua possibilidade de construção de resistência, das micropolíticas.

\section{Referências}

Alverga, A.R. \& Dimenstein, M.(2006) A reforma psiquiátrica eos desafios na desinstitucionalização da loucura. Interface, 10(20), 299-316.

Amarante, P. (2007). Saúde Mental e Atenção Psicossocial. Rio de Janeiro: Fiocruz.

Amorim, A. \& Dimenstein, M. (2009). Loucura e cidade: cenas biopolíticas e incursões (des) institucionalizantes. Fractal: Revista de Psicologia, 21(2), 319-336.

Barros, G. S. (2008). Filtragem Racial: a cor da seleção do suspeito. Revista Brasileira de Segurança Pública, 2(3), 134-155.

Costa A, L. A. \& Fonseca, T. M. G. (2013) Cidades sutis: dispersão urbana e da rede de saúde mental. Psicologia E Sociedade, 25(2), 21-30.

Dunker, C. (2009). A Lógica do Condomínio ou: o Síndico e seus Descontentes. Revista Leitura Flutuante, 1(1). Recuperado de https://revistas.pucsp.br/leituraflutuante/article/view/7623

Eslabão, A. D., Coimbra, V. C., \& Kantorski, L. P. (2017). Rede de cuidado em saúde mental: visão dos coordenadores da estratégia saúde da família. Revista Gaúcha de Enfermagem, 38(1), $85-91$.

Guattari, F. (1992). Caosmose: um novo paradigma estético. Rio de Janeiro: 34.

Lima, M. \& Dimenstein, M. (2016). O apoio matricial em saúde mental: uma ferramenta apoiadora da atenção à crise. Interface, 20(58), 625-635.

Kastrup, V. (2008) O método da cartografia e os quatro níveis da pesquisa-intervenção. In L. R. Castro \& V. L. Besset (Orgs.), Pesquisa-intervenção na infância e juventude (pp. 465-481). Rio de Janeiro: Nau.

Ministério da Saúde. (2004). Saúde mental no SUS: os centros de atenção psicossocial. Secretaria de Atenção à Saúde, Departamento de Ações Programáticas Estratégicas. Brasília, DF: Autor.

Mizoguchi, D. H. (2009). Segmentaricidades: passagens do Leme ao Pontal. São Paulo: Plêiade. 
Palombini, A. L. et al. (2008). Acompanhamento Terapêutico na Rede Pública: a clínica em movimento. Porto Alegre: UFRGS.

Paulon, S. M. (2005). A análise de implicação com ferramenta na pesquisa-intervenção. Psicologia E Sociedade, $17(3), 18-25$.

Pelbart, P. P. (1993). Nau do tempo-rei: sete ensaios sobre o tempo da loucura. Rio de Janeiro: Imago.

Portaria/GMn.3.088, de 23 de dezembro de 2011 . (2011). Institui a Rede de Atenção Psicossocial para pessoas com sofrimento ou transtorno mental e com necessidades decorrentes do uso de crack, álcool e outras drogas, no âmbito do Sistema Único de Saúde (SUS). Brasília, DF: Ministério da Saúde.

Rocha, M. L \& Aguiar, K. F. (2003). Pesquisa-Intervenção e a Produção de Novas Análises. Psicologia: Ciência e Profissão, 23(4), 64-73.

Rotelli, F. \& Amarante, P. (1992). Reforma Psiquiátrica na Itália e no Brasil: aspectos históricos e metodológicos. In B. Bezerra \& P. Amarante (Orgs.), Psiquiatria Sem Hospício: contribuições ao estudo da reforma psiquiátrica (pp. 41-55). Rio de Janeiro: Relume-Dumará.

Rotelli, F., De Leonardis, O., \& Mauri, D. (2001). Desinstitucionalização, outra via. In F. Nicácio (Org.), Desinstitucionalização (pp. 17-59). São Paulo: Hucitec.

Salles, A. C. R. R. \& Mianda, L. (2016). Desvincular-se do manicômio, apropriar-se da vida: persistentes desafios da desinstitucionalização. Psicologia E̊ Sociedade, 28(2), 369-379.

Sinhoretto, J. et al. (2014). A filtragem racial na seleção policial de suspeitos: segurança pública e relações raciais. In I. S. Figueiredo, G. C. Baptista, \& C. S. L. Lima (Orgs.), Coleção Pensando a Segurança Pública (Vol. 5, pp. 121-158). Brasília, DF: Ministério da Justiça/Secretaria Nacional de Segurança Pública.

Virilio, P. (2012, 12 de janeiro). Minha língua estrangeira é a velocidade, é a aceleração do real (Entrevista concedida a Guilherme Soares dos Santos). Egov.UFSC. Recuperado de http:// www.egov.ufsc.br/portal/conteudo/entrevista-virilio-\%E $2 \% 80 \% 9 \mathrm{Cminha-1 \% C3 \% ADngua-}$ estrangeira-\%C3\%A9-velocidade-\%C3\%A9-acelera $\%$ C3\%A7\%C3\%A3o-do-real\%E2\%80\% $9 \mathrm{D}$

\section{JULIA BONGIOVANNI}

https://orcid.org/O000-0002-3690-2001

Psicóloga atua em um CAPS II, especialista em saúde da família e comunidade, mestre em Psicologia Social e Institucional pela UFRGS.

E-mail: juliabongiovanni@yahoo.com.br

\section{ROSANE AZEVEDO NEVES DA SILVA \\ http://orcid.org/0000-0001-6486-0630}

Professora da Universidade Federal do Rio Grande do Sul, Departamento de Psicologia Social e Institucional.

Endereço institucional: Universidade Federal do Rio Grande do Sul, Instituto de Psicologia. Departamento de Psicologia Social e Institucional. Rua Ramiro Barcelos, 2600 - sala 300 D. Santana. 90035003 - Porto Alegre, RS - Brasil.

E-mail: rosane.neves@ufrgs.br 
Submissão em: 28/02/2018

Revisão em: 11/12/2018

Aceite em: 24/01/2019

Financiamento: Não se aplica.

Consentimento de uso de imagem: Não se aplica. 